\title{
Prediction of blood metabolites from milk mid-infrared spectra in early-lactation cows
}

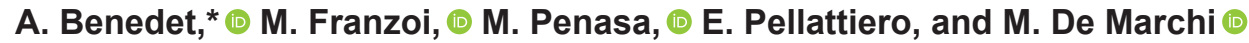 \\ Department of Agronomy, Food, Natural resources, Animals and Environment, University of Padova, 35020 Legnaro (PD), Italy
}

\section{ABSTRACT}

Dairy cows commonly experience an unbalanced energy status in early lactation, and this condition can lead to the onset of several metabolic disorders. Blood metabolic profile testing is a valid tool to monitor and detect the most common early lactation disorders, but blood sampling and analysis are time-consuming and expensive, and the procedure is invasive and stressful for the cows. Mid-infrared (MIR) spectroscopy is routinely used to analyze milk composition, being a cost-effective and nondestructive method. The present study aimed to assess the feasibility of using routine milk MIR spectra for the prediction of main blood metabolites in dairy cows, and to investigate associations between measured blood metabolites and milk traits. Twenty herds of Holstein Friesian, Brown Swiss, or Simmental cows located in Northeast Italy were visited 1 to 4 times between December 2017 and June 2018, and blood and milk samples were collected from all lactating cows within $35 \mathrm{~d}$ in milk. Concentrations of main blood metabolites and milk MIR spectra were recorded from 295 blood and milk samples and used to develop prediction models for blood metabolic traits through backward interval partial least squares analysis. Blood $\beta$-hydroxybutyrate (BHB), urea, and nonesterified fatty acids were the most predictable traits, with coefficients of determination of $0.63,0.58$, and 0.52 , respectively. On the contrary, predictive performance for blood glucose, triglycerides, cholesterol, glutamic oxaloacetic transaminase, and glutamic pyruvic transaminase were not accurate. Associations of blood BHB and urea with their respective contents in milk were moderate to strong, whereas all other correlations were weak. Predicted blood BHB showed an improved performance in detecting cows with hyperketonemia (blood $\mathrm{BHB} \geq 1.2$ $\mathrm{mmol} / \mathrm{L}$ ), compared with commercial calibration equation for milk BHB. Results highlighted the opportunity of using milk MIR spectra to predict blood metabolites

Received May 9, 2019.

Accepted July 22, 2019.

*Corresponding author: anna.benedet@phd.unipd.it and thus to collect routine information on the metabolic status of early-lactation cows at a population level.

Key words: dairy cow, metabolic disorder, $\beta$-hydroxybutyrate, milk infrared spectroscopy

\section{INTRODUCTION}

Dairy cows experience an unbalanced energy status in early lactation as a consequence of the transition from gestation and dry-off to lactogenesis. Metabolic adaptations and high energy demands required for milk production cause a negative energy balance (McArt et al., 2013), which in turn is responsible for the occurrence of several metabolic and reproductive disorders (LeBlanc, 2010; Suthar et al., 2013; Raboisson et al., 2014).

Serum metabolic profile testing is a common method to monitor the metabolic health and nutritional status of dairy cows. Among blood metabolites, glucose, nonesterified fatty acids (NEFA), BHB, and BUN are commonly used as key indicators of metabolic status. Glucose is the main metabolic energy source and the precursor of the lactose synthesis pathway, and thus its demand increases around the time of calving, especially for high-producing cows (Drackley et al., 2001; LeBlanc, 2010). If glucose demand exceeds gluconeogenesis, circulating glucose concentration decreases, impairing the use of this monosaccharide as an energy supply (Ingvartsen, 2006). Insufficient blood glucose levels lead to the mobilization of body energy reserves to cope with negative energy balance; this induces an increase of blood NEFA, which are oxidized in the liver to produce energy. When the oxidizing capacity of the liver is overloaded, circulating ketone bodies are released (Esposito et al., 2014). The abnormal concentration of ketone bodies is known as hyperketonemia (HYK), and it is commonly identified through blood BHB quantification, BHB being the predominant and most stable circulating ketone body (McArt et al., 2012). On the other hand, BUN provides indications about effective RDP intakes, nitrogen utilization efficiency, and nitrogen excretion (Kohn et al., 2005; Macrae et al., 2006; Kume et al., 2008). Moreover, relevant me- 
tabolites such as triglycerides, cholesterol, and liver enzymes [glutamic oxaloacetic transaminase (GOT) and glutamic pyruvic transaminase (GPT)] are often included in serum metabolic profile testing, to provide information on hepatic functionality and identify potential physiological imbalance (González et al., 2011; Bjerre-Harpøth et al., 2012).

Although blood metabolic profile testing is a valid tool to detect common disorders in early lactation, blood sampling and analysis are time-consuming and expensive, and the procedure is invasive and stressful for cows. For this reason, large-scale blood metabolic profiling is not feasible. Thanks to routine data availability, milk has been widely investigated as an alternative to blood as a biological matrix for assessing and monitoring health traits through mid-infrared (MIR) spectroscopy (Grelet et al., 2016). Predicted milk metabolic indicators, such as acetone, BHB, and fat-to-protein ratio $(\mathbf{F} / \mathbf{P})$, have been used to monitor metabolic status at the herd level (van Knegsel et al., 2010; Santschi et al., 2016; Tatone et al., 2017), but given their moderate diagnostic accuracy, they have been considered improper diagnostic tools at an individual cow level (van Knegsel et al., 2010; Chandler et al., 2018). To increase the diagnostic capability of data derived from milk MIR spectra, van der Drift et al. (2012b) and Chandler et al. (2018) have developed linear and logistic regression models combining available test-day information such as milk production and composition, milk ketone bodies, DIM, and parity, to assess metabolic disorders. Moreover, several efforts have been made to directly predict blood metabolites at the individual cow level using milk MIR spectra (Belay et al., 2017; Grelet et al., 2019; Luke et al., 2019) or merging them with milk composition and producer-reported variables (Pralle et al., 2018; Grelet et al., 2019). Using routine milk MIR data to predict cow metabolic status would not only prevent the need for expensive analyses but also allow recording of information at a population level. Therefore, the aims of the present study were to assess the feasibility of using routine milk MIR spectra for the prediction of blood metabolites in dairy cows and to investigate the associations between measured blood metabolites and predicted milk traits.

\section{MATERIALS AND METHODS}

\section{Data Collection}

Animal sampling and handling protocols were approved by the Ethical Committee for the Care and Use of Experimental Animals of the University of Padova and carried out in accordance with the EU directive 2010/63/EU for animal experiments.
Twenty herds of Holstein Friesian, Brown Swiss, or Simmental cows (herd size from 15 to 500 cows) located in Northeast Italy were visited 1 to 4 times from December 2017 to June 2018. On average, 10 lactating cows, from 5 to 35 DIM and from parity 1 to 10 , were sampled at each visit. Four herds were visited more than once, with a time interval between visits ranging from 5 to 28 d. In total, 194 lactating cows were sampled, from a minimum of 3 to a maximum of 41 cows per herd. Moreover, $64 \%$ of the animals were sampled once, and $20 \%, 15 \%$, and $1 \%$ were sampled 2,3 , and 4 times, respectively. Milk and blood samples were collected from the same cow at each sampling. Individual milks were collected following the same procedure used during routine cow milk testing, in which each sample is representative of the composition of the entire milking. Samples were immediately added with preservative (Bronopol, 2-bromo-2-nitropropan-1,3-diol, Knoll Pharmaceuticals, Nottingham, UK) and stored in portable refrigerators at $4^{\circ} \mathrm{C}$. One blood sample was collected within $1 \mathrm{~h}$ from the end of morning (259 samples) or afternoon milking (36 samples) by jugular venipuncture into vacuum-sealed tubes (9-mL Vacutainer; Becton Dickinson and Company, Franklin Lakes, NJ) containing lithium heparin and gently inverted several times to prevent blood clotting.

\section{Milk and Blood Analysis}

Milk samples were transferred to the laboratory of the South Tyrolean Dairy Association (Bolzano, Italy) and analyzed for fat, protein, casein, and lactose percentages, MUN, and BHB concentration (mBHB) using MilkoScan FT7 (Foss, Hillerød, Denmark). The device was calibrated with the equations developed and commercialized by Foss, and milk MIR spectra were standardized according to manufacturer guidelines. Fat-to-protein ratio was calculated from predicted milk composition traits. Somatic cell count was analyzed by Fossomatic (Foss), and values were transformed to SCS through the formula SCS $=3+\log _{2}(\mathrm{SCC} / 100,000)$.

Blood samples were centrifuged at $1,800 \times g$ for 15 min at $4^{\circ} \mathrm{C}$ to separate plasma, which was stored in 2-mL Eppendorf tubes at $-20^{\circ} \mathrm{C}$. Frozen plasma samples were sent to the Clinical Biochemistry Laboratory of the Experimental Zooprophylactic Institute of Lombardy and Emilia Romagna (IZSLER, Brescia, Italy) and analyzed for metabolic parameters through an ILab 650 chemistry analyzer (Instrumentation Laboratory SpA, Milano, Italy) using colorimetric assay for NEFA, enzymatic kinetic colorimetric assay for BHB, kinetic assay (IFCC, International Federation of Clinical Chemistry and Laboratory Medicine) for GOT and GPT, dichromatic colorimetric end point assay (Allain 
et al., 1974) for total cholesterol, colorimetric trinder end point assay for glucose, colorimetric end point assay for triglycerides, and urease test for BUN.

\section{Associations Between Blood Metabolic Parameters and Milk Traits}

The first observation available for each cow was used to investigate the phenotypic associations between blood metabolites, as well as the phenotypic associations of blood metabolites with milk metabolic parameters and quality traits. In particular, Pearson correlations between the residuals were assessed after adjusting metabolite concentrations for the effects of parity, week in milk, breed, and herd-month of sampling. The effect of sampling time (morning and afternoon milking) was also tested, but it was not statistically significant in explaining the variation of the studied traits and thus was excluded from the final model. Statistical analysis was performed using the MIXED procedure of SAS software version 9.4 (SAS Institute Inc., Cary, NC), according to the following linear model:

$$
\mathrm{y}_{i j k l m}=\mu+\mathrm{P}_{i}+\mathrm{W}_{j}+\mathrm{B}_{k}+\mathrm{HM}_{l}+\varepsilon_{i j k l m},
$$

where $\mathrm{y}$ is the dependent variable (blood metabolites, milk production, or quality traits); $\mu$ is the overall intercept of the model; $\mathrm{P}_{i}$ is the fixed effect of the $i$ th parity of the cow ( $i=$ primiparous or multiparous); $\mathrm{W}_{j}$ is the fixed effect of the $j$ th class of week of lactation of the cow $(j=1$ to 5$) ; \mathrm{B}_{k}$ is the fixed effect of the $k$ th breed of the cow $(k=$ Brown Swiss, Holstein-Friesian, or Simmental); $\mathrm{HM}_{l}$ is the random effect of the lth herd-month of sampling ( $l=1$ to 22 ); and $\varepsilon$ is the random residual.

\section{Prediction Models}

Milk MIR spectra collected by the South Tyrolean Dairy Association were used to develop MIR prediction models for blood metabolites. Milk MIR spectra were paired with the reference values for blood and transformed from transmittance $(\mathrm{T})$ to absorbance $(\mathrm{A})$ by applying the formula: $\mathrm{A}=\log _{10}(1 / \mathrm{T})$. The data set was checked for spectral outliers using Mahalanobis distance (threshold $=3.0$ ), and no outliers were detected. Following infrared instrument manufacturer specifications (Foss), spectral wavelengths in regions commonly associated with high variability and low repeatability induced by water content of milk were removed. Thus, the final data set comprised 450 spectral variables in the intervals 964.5 to $1,562.5 \mathrm{~cm}^{-1}, 1,720.7$ to $2,291.7$ $\mathrm{cm}^{-1}$, and $2,415.1$ to $2,970.7 \mathrm{~cm}^{-1}$, from 295 samples. Blood BHB was normalized via $\log _{10}$ transformation.
Prediction models and fitting statistics were computed using a macro developed in SAS software version 9.4 (SAS Institute Inc.). Backward interval partial least squares (BiPLS) analysis was performed according to Zou et al. (2007), to improve predictive ability of the developed models. Milk MIR spectra were divided into 45 intervals across the MIR range from 964.5 to $2,970.7 \mathrm{~cm}^{-1}$, each including 10 spectral variables, and the partial least squares (PLS) procedure of SAS was iteratively performed excluding one interval at a time. Predicted residual error sum of squares (PRESS) was calculated for each iteration. The interval to be excluded from the subsequent BiPLS round was the one resulting in the lowest PRESS statistic when left out. The procedure was iterated until only 1 interval remained (Xiaobo et al., 2010). For each iteration, the number of latent variables to perform the PLS procedure was defined as the minimum number of latent variables from 1 to 10 to achieve the lowest PRESS, with $P>0.10$. Root mean square error in leave-one-out cross validation was calculated for each BiPLS round, and the model with the best performance was selected as the final prediction model. For comparison, PLS was performed using the same parameters considered for BiPLS, including the whole spectrum to develop the prediction model. Calibration outliers were defined as observations having a residual between predicted and observed values in calibration more than 3 standard deviations (SD) from the residual average. The BiPLS procedure was repeated after calibration outliers exclusion.

The external validation was conducted by randomly assigning 1 third of the sampled cows to the validation set and 2 thirds of the samples to the calibration set. The external validation was iterated 3 times, each time over a different third of cows, and reported fitting statistics were the average of the fitting statistics of the 3 iterations. Fitting statistics of PLS and BiPLS models were the standard error in cross validation and in external validation, the coefficient of determination in cross validation $\left(\mathbf{R}_{\mathbf{c v}}^{2}\right)$ and in external validation $\left(\mathbf{R}_{\mathbf{v}}^{2}\right)$, and the ratio of performance to deviation in cross validation and external validation, calculated as the ratio between $\mathrm{SD}$ and root mean square error in leave-one-out cross validation and between SD and root mean square error in external validation, respectively.

\section{RESULTS AND DISCUSSION}

\section{Descriptive Statistics}

Descriptive statistics of blood metabolites and milk traits are summarized in Table 1. Among blood components, NEFA and BHB were the most variable traits, 
Table 1. Descriptive statistics of blood metabolites, milk yield, and composition traits

\begin{tabular}{|c|c|c|c|c|c|c|}
\hline Trait $^{1}$ & $n^{2}$ & Mean & $\mathrm{SD}$ & $\mathrm{CV}, \%$ & Minimum & Maximum \\
\hline $\mathrm{BHB}, \mathrm{mmol} / \mathrm{L}$ & 295 & 0.73 & 0.46 & 63 & 0.28 & 3.55 \\
\hline $\mathrm{NEFA}, \mathrm{mmol} / \mathrm{L}$ & 295 & 0.48 & 0.35 & 73 & 0.01 & 2.23 \\
\hline Glucose, mmol/L & 295 & 3.03 & 0.71 & 23 & 1.70 & 11.30 \\
\hline Triglycerides, mmol/L & 295 & 0.09 & 0.05 & 56 & 0.03 & 0.93 \\
\hline Cholesterol, mmol/L & 295 & 3.19 & 1.08 & 34 & 0.49 & 7.00 \\
\hline \multicolumn{7}{|l|}{ Milk } \\
\hline Milk yield, kg/d & 286 & 18.69 & 5.38 & 29 & 7.00 & 36.10 \\
\hline Fat, $\%$ & 295 & 4.13 & 0.93 & 22 & 1.56 & 7.93 \\
\hline Protein, \% & 295 & 3.32 & 0.41 & 12 & 2.38 & 5.03 \\
\hline $\mathrm{F} / \mathrm{P}$ & 295 & 1.25 & 0.27 & 22 & 0.48 & 2.37 \\
\hline Casein, \% & 295 & 2.55 & 0.34 & 13 & 1.67 & 4.14 \\
\hline Lactose, $\%$ & 295 & 4.76 & 0.22 & 13 & 4.08 & 5.27 \\
\hline
\end{tabular}

${ }^{1} \mathrm{NEFA}=$ nonesterified fatty acids; GOT $=$ glutamic oxaloacetic transaminase; GPT $=$ glutamic pyruvic transaminase $\mathrm{F} / \mathrm{P}=$ fat-to-protein ratio; $\mathrm{mBHB}=$ milk $\mathrm{BHB}$.

${ }^{2} \mathrm{n}=$ number of samples.

${ }^{3}$ Fourier-transform infrared spectroscopy analysis may lead to negative values.

with coefficients of variation of 73 and $63 \%$, respectively. Considering blood NEFA concentration $\geq 0.70$ $\mathrm{mmol} / \mathrm{L}$ as a critical threshold to identify cows with high body reserves mobilization (McArt et al., 2013), $22.4 \%$ of blood samples were above this threshold. On average, descriptive statistics of NEFA and prevalence of high NEFA concentrations were in agreement with findings of Luke et al. (2019) in early-lactation Holstein cows. The percentage of hyperketonemic samples (BHB $\geq 1.2 \mathrm{mmol} / \mathrm{L}$; McArt et al., 2012) was 9.8\%. Although mean blood $\mathrm{BHB}$ and the percentage of samples with elevated BHB concentrations agreed with Pralle et al. (2018), lower and more variable statistics were reported by Grelet et al. (2019) and Luke et al. (2019) in Holstein cows, probably because of the longer observation period considered in Grelet et al. (2019; 1 to 50 DIM) and Luke et al. (2019; 5 to 49 DIM) compared with the present study. The BUN averaged 3.82 $\mathrm{mmol} / \mathrm{L}$ and had coefficient of variation of $36 \%$, which is lower and less variable compared with the results of Luke et al. (2019). Only 3 samples showed abnormal concentrations of BUN (1 sample below $1.7 \mathrm{mmol} / \mathrm{L}$ and 2 samples above $6.8 \mathrm{mmol} / \mathrm{L}$; Butler et al., 1996; Macrae et al., 2006), indicating a low prevalence of RDP-related disorders. Glucose was the least variable metabolic trait, with coefficient of variation of $23 \%$. Average glucose concentration was $3.03 \mathrm{mmol} / \mathrm{L}$, which is slightly lower than that reported by Grelet et al. (2019). In our data set, 9.5\% of samples had glucose concentrations $\leq 2.2 \mathrm{mmol} / \mathrm{L}$, which is a critical cutoff for hypoglycemia (Gordon et al., 2013).
Means of milk production and composition traits were comparable with those reported in a recent study conducted among multibreed herds in Northeast Italy (Visentin et al., 2018). The mBHB averaged 0.02 $\mathrm{mmol} / \mathrm{L}$, which is lower than concentrations from previous reports (around 0.07 to $0.08 \mathrm{mmol} / \mathrm{L}$; van der Drift et al., 2012a; Chandler et al., 2018; Pralle et al., 2018).

\section{Associations Between Blood Metabolic Parameters and Milk Traits}

Pearson correlations between blood metabolic parameters corrected for environmental and genetic (breed) effects are summarized in Table 2. The strongest positive correlation was observed between $\mathrm{BHB}$ and NEFA $(0.45 ; P<0.001)$; this estimate was close to that reported by Luke et al. (2019) and much higher than the one assessed by González et al. (2011), who observed a weak and not different from zero association (0.11) between measured blood BHB and NEFA in early-lactation Holstein cows. The lower correlation estimated by González et al. (2011) could be due to the much higher mean BHB concentration calculated in their study $(1.45 \mathrm{mmol} / \mathrm{L})$, which notably exceeded both the mean BHB concentration of the present study $(0.73 \mathrm{mmol} / \mathrm{L})$ and the cutoff commonly used to identify HYK $(1.2 \mathrm{mmol} / \mathrm{L})$. On the other hand, average NEFA reported in González et al. (2011; 0.54 $\mathrm{mmol} / \mathrm{L}$ ) was similar to that reported in the current study $(0.48 \mathrm{mmol} / \mathrm{L})$. The second strongest relation- 
Table 2. Pearson correlations between blood metabolites at first observation of each cow $(\mathrm{n}=194)$, corrected for parity, week in milk, breed, and herd-month of sampling ${ }^{1}$

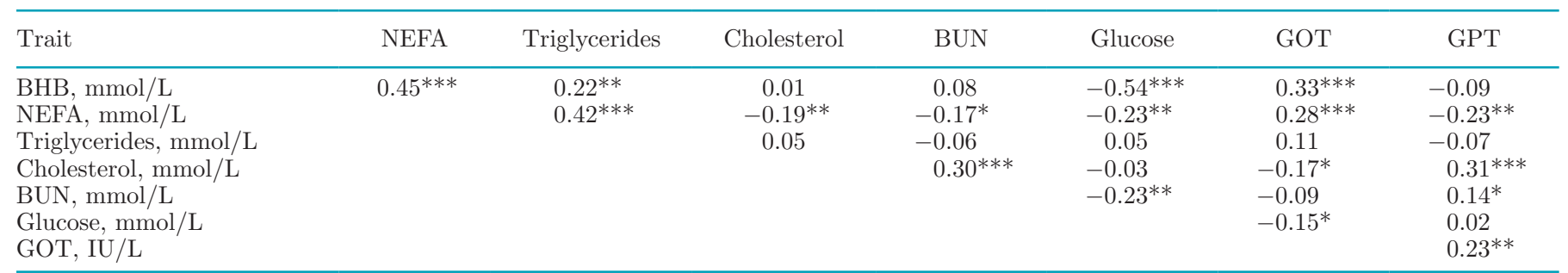

${ }^{1} \mathrm{NEFA}=$ nonesterified fatty acids; GOT $=$ glutamic oxaloacetic transaminase; GPT $=$ glutamic pyruvic transaminase, $\mathrm{IU} / \mathrm{L}$.

${ }^{*} P<0.05,{ }^{* *} P<0.01,{ }^{* * *} P<0.001$.

ship was observed between NEFA and triglycerides (0.42; $P<0.001)$; moreover, triglycerides showed weak but significant correlation with BHB $(0.22 ; P<0.001)$. Conversely, González et al. (2011) concluded that triglycerides cannot be considered adequate indicators of lipomobilization, reporting nonsignificant correlations of triglycerides with NEFA and BHB. Moderate to weak correlations of GOT with $\mathrm{BHB}(0.33 ; P<0.001)$ and NEFA $(0.28 ; P<0.01)$ were observed in the present study, whereas González et al. (2011) estimated correlations of 0.16 between GOT and BHB, and -0.46 between GOT and NEFA.

As expected, glucose concentration was negatively associated with blood BHB $(-0.54 ; P<0.001)$, NEFA $(-0.23 ; P<0.01)$, and BUN $(-0.23 ; P<0.01)$, highlighting a significant association between hypoglycemia, fat mobilization, and circulating nitrogen. The relationship between BHB and glucose was also reported by González et al. (2011), who estimated a significant negative correlation $(-0.63)$ between these 2 traits. Similar to results reported in previous studies (González et al., 2011; Luke et al., 2019), a weak negative association was estimated between BUN and NEFA $(-0.17 ; P<0.05)$, and a very low nonsignificant correlation was assessed between BUN and BHB (0.08).

Pearson correlations between the linear mixed model residuals of blood metabolites and those of milk BHB, $\mathrm{F} / \mathrm{P}$, and quality traits are reported in Table 3. The correlation between $\mathrm{mBHB}$ and blood $\mathrm{BHB}$ was 0.58 $(P<0.001)$. Similarly, van der Drift et al. (2012a) estimated a correlation of 0.52 between blood and milk BHB, and Chandler et al. (2018) reported correlations between 0.40 and 0.62 for Holstein cows. Like blood BHB, mBHB showed significant moderate correlations with glucose $(-0.41 ; P<0.001)$ and NEFA $(0.38 ; P$ $<0.001)$, and weak associations with GOT $(0.20 ; P<$ $0.01)$ and triglycerides $(0.16 ; P<0.05)$. Associations between $\mathrm{F} / \mathrm{P}$ and other blood metabolites were in the same direction but weaker than those between mBHB and blood parameters (Table 3), suggesting that mBHB could be used as a more accurate indicator of metabolic disorders than $\mathrm{F} / \mathrm{P}$, supporting previous findings (van Knegsel et al., 2010). The strongest association was observed between MUN and BUN $(0.70 ; P<0.001)$, similar to results reported by Wittwer et al. (1999). On the other hand, a weak correlation between MUN and glucose was observed $(-0.25 ; P<0.001)$, which resembled the association between BUN and glucose (Table 2). The moderate associations of protein and CN percentage with blood BHB $(-0.29$ and -0.32 , respectively; $P<0.001)$ can be explained by the detrimental effect that HYK exerts on milk protein content (Benedet et al., 2019). Moreover, CN percentage was the trait most strongly correlated with GOT $(-0.25 ; P$ $<0.001$ ), suggesting that impaired hepatic functionality leads to reduced milk protein synthesis. Lactose was moderately $(P<0.001)$ associated with NEFA $(-0.31)$ and cholesterol $(0.26)$. The negative association between milk lactose content and NEFA could be explained by the detrimental effect that metabolic imbalance has on milk quality (Benedet et al., 2019), whereas the correlation between lactose and cholesterol could be related to increased milk production, as cholesterol showed weak but significant $(P<0.05)$ negative correlations with fat and protein percentage (Table 3 ).

\section{Prediction of Blood Metabolites}

For each blood metabolite, specific spectral regions were selected through BiPLS procedure to develop the prediction models. Useful wavenumbers for the most important metabolic traits are depicted in Figure 1. Wavenumbers selected by BiPLS for BUN, NEFA, and BHB calibration models included the spectral region between 1,450 and 1,200 $\mathrm{cm}^{-1}$, known to be associated with acetone content in milk, which is an indicator of subclinical ketosis (Heuer et al., 2001). Moreover, the calibrations of BUN, NEFA, and BHB include spectral regions typical of milk lactose $\left(1,250\right.$ to $\left.1,000 \mathrm{~cm}^{-1}\right)$ and fat content (1,450 to $1,390 \mathrm{~cm}^{-1}$; Grelet et al., 2015). Considering the negative association between milk lactose percentage and BHB in blood and milk (Benedet 
et al., 2019), the inclusion of spectral regions typical for lactose content in the BHB prediction model was somewhat expected (Table 3). Finally, BiPLS for BHB prediction also included wavelengths between 1,500 and $1,400 \mathrm{~cm}^{-1}$, typical of milk protein content (De Marchi et al., 2014). Comprehensive descriptions of selected wavelengths with associated compositions are listed in Supplemental Table S1 (https://doi.org/10.3168/jds .2019-16937).

Fitting statistics of developed models greatly varied among blood metabolites (Table 4). Prediction models for BHB, BUN, and NEFA had $\mathrm{R}_{\text {cv }}^{2}$ of $0.64,0.54$, and 0.53 , and $\mathrm{R}_{\mathrm{v}}^{2}$ of $0.63,0.58$, and 0.52 , respectively. The ratio of performance to deviation in cross validation ranged from 1.45 (NEFA) to 1.61 (BHB), and the ratio of performance to deviation in external validation from 1.41 (NEFA) to 1.58 (BHB). Glucose, triglycerides, cholesterol, GOT, and GPT were predicted with less accuracy compared with BHB, BUN, and NEFA; indeed, $\mathrm{R}_{\mathrm{cv}}^{2}$ and $\mathrm{R}_{\mathrm{v}}^{2}$ were smaller than 0.50 . The accuracy of prediction of BHB was slightly higher compared with other studies (Belay et al., 2017; Pralle et al., 2018; Luke et al., 2019), and similar to the results of Grelet et al. (2019), who obtained $\mathrm{R}_{\mathrm{cv}}^{2}$ of 0.70 . Grelet et al. (2019) concluded that the model was not appropriate for providing exact BHB values, but it was accurate enough for distinguishing between high and low blood BHB concentrations. Similarly, our results suggest that prediction models could be used to discriminate between low, medium, and high BHB concentrations and, thus, between cows with or without HYK. The moderate accuracy of blood NEFA prediction was reported also by Luke et al. (2019), who observed $R^{2}$ from 0.45 to 0.61 in external and random validation, respectively, whereas Grelet et al. (2019) reported lower $\mathrm{R}_{\mathrm{cv}}^{2}(0.39)$ for NEFA. Despite the moderate accuracy, predicted blood NEFA may reasonably be used to facilitate the detection of negative energy balance in sampled cows. The prediction model for BUN showed lower-than- expected performance, especially compared with the findings of Luke et al. (2019), who reported $\mathrm{R}_{\mathrm{cv}}^{2}$ and $\mathrm{R}_{\mathrm{v}}^{2}$ of 0.90 . This could be due to the limited range of variation observed in our study for BUN concentration compared with that of Luke et al. (2019). This hypothesis is supported by the fact that external validation conducted by Luke et al. (2019) on a data set with means and variation similar to the present study showed a low $\mathrm{R}_{\mathrm{v}}^{2}(0.35)$. Nevertheless, MUN analysis is routinely provided in milk recording systems, and a moderate to strong positive Pearson correlation exists between MIR-predicted MUN and measured BUN in the present study $(\mathrm{r}=0.70$ for corrected data and $\mathrm{r}=$ 0.85 for raw data; $P<0.001$ ). For this reason, MUN can be considered a reliable tool to monitor nitrogen utilization (Jonker et al., 1998; Wittwer et al., 1999). To our knowledge, this is the first study that attempted to predict bovine blood triglycerides, cholesterol, GOT, and GPT using milk MIR spectra; the prediction models for these traits were not accurate. Regarding glucose, low $\mathrm{R}_{\mathrm{cv}}^{2}$ for this trait was already observed by Grelet et al. (2019), who attributed the difficulties of developing a reliable model to the limited variability of glucose. As a matter of fact, the low variability of glucose observed by Grelet et al. (2019), expressed by a coefficient of variation of $15 \%$, was close to the coefficient of variation (17\%) observed in the present study after removal of outliers (Table 4). Limited variability could also be a possible reason for low predictive accuracy for the other traits (triglycerides, cholesterol, GOT, and GPT), along with the difficulties of detecting low blood concentrations (Table 1 and Table 4) and the absence of a direct correspondence or relationship with milk traits (Table 3 ).

Overall, the comparison of MIR models developed in different studies is difficult; prediction performances of blood traits are influenced by blood sampling techniques (e.g., time between milk and blood collection, and standardization) and the validation procedures used. In our

Table 3. Pearson correlations between blood metabolites, milk BHB, and milk quality traits at first observation of each cow $(\mathrm{n}=194)$, corrected for parity, week in milk, breed, and herd-month of sampling ${ }^{1}$

\begin{tabular}{|c|c|c|c|c|c|c|c|c|}
\hline Trait & $\begin{array}{l}\mathrm{mBHB}, \\
\mathrm{mmol} / \mathrm{L}\end{array}$ & $\mathrm{F} / \mathrm{P}$ & $\begin{array}{c}\text { Fat, } \\
\%\end{array}$ & $\begin{array}{c}\text { Protein, } \\
\%\end{array}$ & $\begin{array}{c}\text { Casein, } \\
\%\end{array}$ & $\begin{array}{c}\text { Lactose, } \\
\%\end{array}$ & $\begin{array}{l}\text { MUN, } \\
\mathrm{mg} / \mathrm{dL}\end{array}$ & SCS \\
\hline BHB, mmol/L & $0.58^{* * *}$ & $0.34^{* * *}$ & $0.23^{* *}$ & $-0.29^{* * *}$ & $-0.32^{* * *}$ & $-0.25^{* * *}$ & $0.18^{*}$ & -0.06 \\
\hline NEFA, mmol/L & $0.38 * * *$ & $0.23^{* *}$ & $0.17^{*}$ & $-0.21^{* *}$ & $-0.23^{* *}$ & $-0.31^{* * *}$ & -0.07 & 0.03 \\
\hline Cholesterol, mmol/L & -0.10 & -0.10 & $-0.16^{*}$ & $-0.16^{*}$ & -0.12 & $0.26^{* * *}$ & $0.14^{*}$ & $-0.16^{*}$ \\
\hline $\mathrm{BUN}, \mathrm{mmol} / \mathrm{L}$ & -0.06 & 0.08 & 0.02 & -0.14 & $-0.15^{*}$ & 0.08 & $0.70^{* * *}$ & -0.02 \\
\hline Glucose, $\mathrm{mmol} / \mathrm{L}$ & $-0.41^{* * *}$ & $-0.19^{* *}$ & -0.13 & $0.18^{*}$ & $0.16^{*}$ & 0.10 & $-0.25^{* * *}$ & $0.19^{* *}$ \\
\hline
\end{tabular}

${ }^{1} \mathrm{NEFA}=$ nonesterified fatty acids $; \mathrm{mBHB}=$ milk BHB; $\mathrm{F} / \mathrm{P}=$ fat-to-protein ratio GOT $=$ glutamic oxaloacetic transaminase; $\mathrm{GPT}=$ glutamic pyruvic transaminase.

${ }^{*} P<0.05,{ }^{* *} P<0.01,{ }^{* * *} P<0.001$. 
study, similar to that of Pralle et al. (2018), a stringent protocol for milk and blood sample collection was applied to obtain blood and milk samples within $1 \mathrm{~h}$. Conversely, in other recent studies (Grelet et al., 2019; Luke et al., 2019), sampling procedures were characterized by longer intervals between milk and blood collection. Moreover, only a few studies included an external validation step, using different approaches (Belay et al., 2017; Pralle et al., 2018; Luke et al., 2019). For instance, Luke et al. (2019) used data from an independent farm as an external validation data set. A similar or a herd-by-herd approach is useful to avoid possible overly optimistic results from cross-validation (Wang and Bovenhuis, 2019). However, due to the limited number of early-lactation cows available in each herd, a herd-by-herd validation approach was not possible in the present study. This is a potential limitation that should be considered in future investigations.

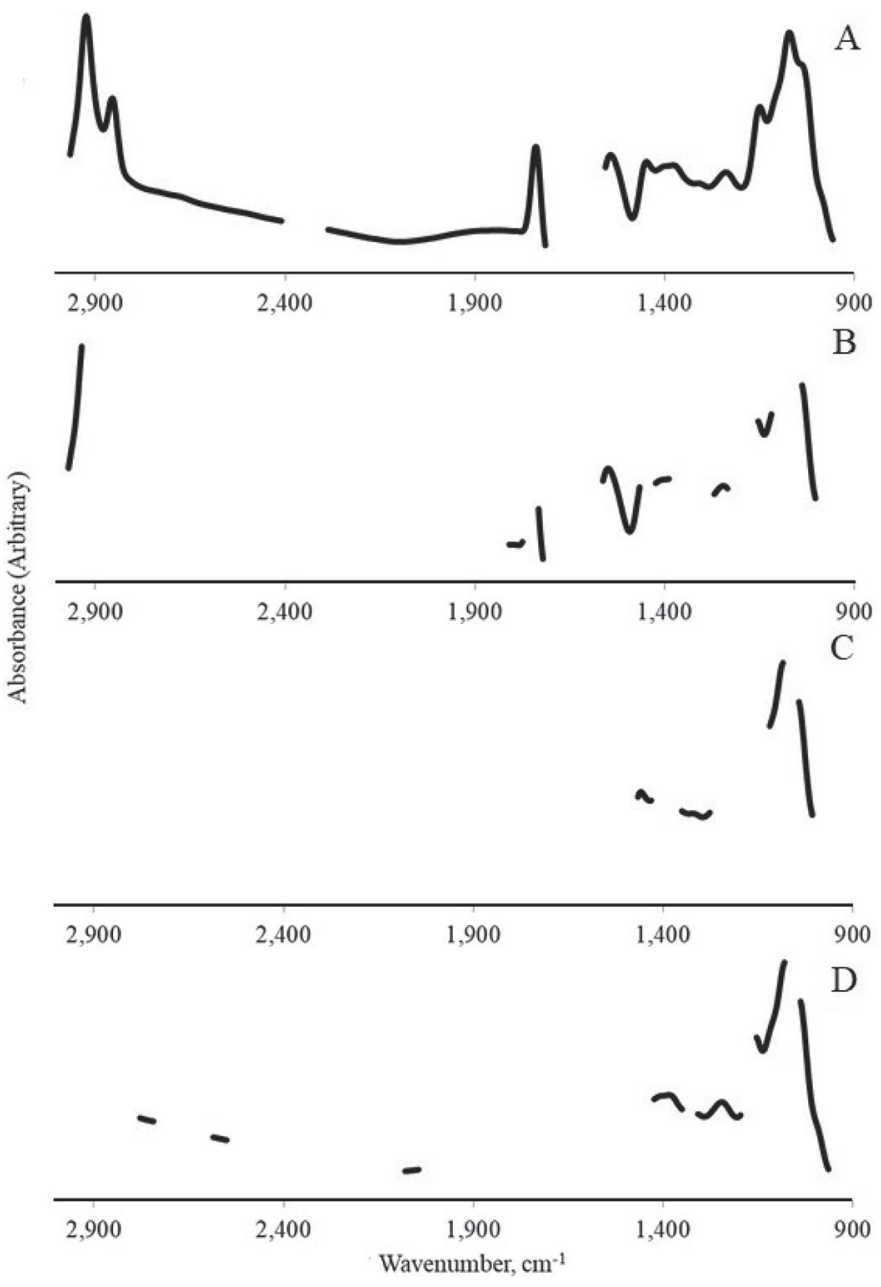

Figure 1. Whole (A) and selected wavenumber variables or spectral regions for predicting BUN (B), nonesterified fatty acids (C), and BHB (D).

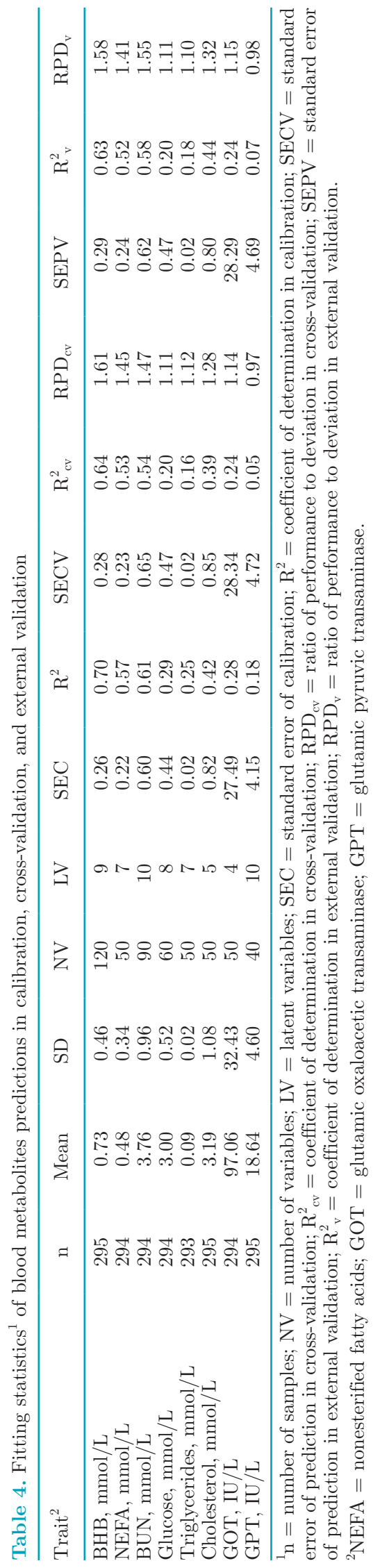


Table 5. Accuracy, sensitivity, specificity, and predictive values (95\% CI) of predicted metabolic indicators for hyperketonemia diagnosis

\begin{tabular}{|c|c|c|c|}
\hline \multirow[b]{2}{*}{ Diagnostic statistic } & \multicolumn{3}{|c|}{ Metabolic indicator $^{2}$} \\
\hline & $\mathrm{BHB}_{\mathrm{cv}}$ & $\mathrm{mBHB}$ & $\mathrm{F} / \mathrm{P}$ \\
\hline Recommended threshold ${ }^{3}$ & $1.2 \mathrm{mmol} / \mathrm{L}$ & $0.14 \mathrm{mmol} / \mathrm{L}$ & 1.5 \\
\hline Accuracy & $0.92(0.88-0.95)$ & $0.89(0.86-0.93)$ & $0.85(0.81-0.89)$ \\
\hline Sensitivity & $0.28(0.11-0.44)$ & $0.14(0.05-0.33)$ & $0.28(0.11-0.47)$ \\
\hline Specificity & $0.98(0.97-1.00)$ & $0.98(0.96-1.00)$ & $0.91(0.88-0.95)$ \\
\hline Positive predictive value & $0.67(0.40-0.93)$ & $0.40(0.10-0.70)$ & $0.26(0.10-0.41)$ \\
\hline Negative predictive value & $0.93(0.90-0.96)$ & $0.91(0.88-0.95)$ & $0.92(0.89-0.95)$ \\
\hline
\end{tabular}

\section{Discriminant Ability of Predicted Blood and Milk Indicators}

Predicted blood and milk BHB and $\mathrm{F} / \mathrm{P}$ were tested for their performance in discriminating between cows affected or not affected by HYK. To achieve this goal, samples with predicted BHB in cross-validation $\left(\mathbf{B H B}_{\mathbf{c v}}\right)$ of $1.2 \mathrm{mmol} / \mathrm{L}$ or higher were classified as indicating HYK, according to McArt et al., (2013). On the other hand, a concentration of $0.14 \mathrm{mmol} / \mathrm{L}$ for mBHB was selected as the cutoff to identify cows with potential HYK, as reported in Renaud et al. (2019). Although recognized as a milk HYK indicator with lower accuracy than that of ketone bodies (van Knegsel et al., 2010), F/P has the advantage of being an easy-access indirect indicator of HYK, computed from robustly predicted milk composition traits (fat and protein content). A cutoff of 1.5 was proposed by van Knegsel et al. (2010), and we applied this on our recorded data to discriminate between cows with or without HYK. Classification obtained through this test was compared with results from reference blood analyses to determine the discriminant capabilities of $\mathrm{BHB}_{\mathrm{cv}}, \mathrm{mBHB}$, and $\mathrm{F} / \mathrm{P}$.

Accuracy, sensitivity, specificity, positive predictive value, and negative predictive value of HYK determination were computed for each metabolic indicator (Table $5)$. Accuracy is the proportion of correctly assigned observations (HYK or not) among all observations tested, and it ranged from $0.85(\mathrm{~F} / \mathrm{P})$ to $0.92\left(\mathrm{BHB}_{\mathrm{cv}}\right)$ for the predictors tested in this analysis. Although different but satisfactory accuracies were estimated, a poor sensitivity (0.14 to 0.28 ), defined as the ability to detect cows with HYK, was observed for all metabolic indicators. The $\mathrm{BHB}_{\mathrm{cv}}$ showed the best positive predictive value (0.67), which is the probability that an animal predicted positive for HYK has a measured blood BHB $\geq 1.2 \mathrm{mmol} / \mathrm{L}$, whereas $\mathrm{F} / \mathrm{P}$ showed the worst positive predictive value (0.26) and, consequently, a high proportion of false positives. This is in accordance with the findings of van Knegsel et al. (2010), who reported less capability of $\mathrm{F} / \mathrm{P}$ than ketone bodies to detect cows affected by HYK. Overall, $\mathrm{BHB}_{\mathrm{cv}}$ showed the most promising combination of specificity (0.98) and negative predictive value (0.93), these being the probability that the test result is negative for HYK when the disorder is not present (specificity) and that HYK is not present when the cow is tested negative for HYK (negative predictive value).

Several attempts to classify cows with or without HYK through prediction models based on milk MIR spectra, traits, and performance variables have been described in literature. Considering mBHB, although using thresholds lower than $0.14 \mathrm{mmol} / \mathrm{L}$ to identify HYK, van der Drift et al. (2012b; $0.07 \mathrm{mmol} / \mathrm{L})$ and Chandler et al. (2018; $0.10 \mathrm{mmol} / \mathrm{L})$ did not report results more promising than ours, observing high falsepositive rates and limited accuracy and efficiency. Renaud et al. (2019) obtained greater sensitivity and specificity than we observed in the present study. Nevertheless, the same authors concluded that the low prevalence of HYK in the population limited the statistical robustness of the test and that a larger number of cows should have been enrolled to achieve adequate performance. Similar limitations should be taken into account in considering the low sensitivity of $\mathrm{BHB}_{\mathrm{cy}}$. True positive cases of HYK detected through this test had measured blood BHB concentrations $\geq 1.37$ $\mathrm{mmol} / \mathrm{L}$, averaging $2.55 \mathrm{mmol} / \mathrm{L}$. Conversely, the average measured BHB of misclassified HYK cases was $1.53 \mathrm{mmol} / \mathrm{L}$, suggesting that the higher the concentration, the greater the ability to discriminate samples with BHB below or above the HYK threshold. Thus, a much higher number of cows with HYK would have contributed to achieve more power and accuracy in predicting elevated BHB concentrations. To increase MIR predicting power, Pralle et al. (2018) combined 
producer-reported variables and milk composition traits with milk MIR spectra. However, due to the marginal improvement in model performance, Pralle et al. (2018) concluded that there are more advantages in considering these variables for predicting HYK status separately.

\section{CONCLUSIONS}

In the present study, milk and blood samples of early-lactation dairy cows were collected and analyzed to assess metabolic status information. Moderate to strong correlations between blood metabolites, and weak to moderate associations between blood and milk metabolic indicators in early lactation were observed. Although the first attempt at predicting bovine blood triglycerides, cholesterol, GOT, and GPT using milk MIR spectra did not show accurate results, milk MIR spectra demonstrated potential for predicting important blood metabolites, in particular blood BHB. Predicted blood $\mathrm{BHB}$ was more strongly correlated with measured blood BHB than with $\mathrm{mBHB}$, showing the most powerful ability to discriminate hyperketonemic cows. Therefore, blood metabolites predicted through milk MIR spectra are an important source of routine information on the metabolic status of early-lactation cows. This is a prelude to large-scale phenotyping of predicted blood $\mathrm{BHB}$ for use in breeding programs to reduce cows' susceptibility to HYK postpartum. We aim to increase the sample size in the near future, to increase the variability of the calibration data set and improve the accuracy of prediction models.

\section{ACKNOWLEDGMENTS}

The authors thank the Clinical Biochemistry Laboratory of the Experimental Zooprophylactic Institute of Lombardy and Emilia Romagna (IZSLER, Brescia, Italy) and the South Tyrolean Dairy Association (Bolzano, Italy) for providing data used in the present study and for technical support.

\section{REFERENCES}

Allain, C. C., L. S. Poon, C. S. Chan, W. Richmond, and P. C. Fu. 1974. Enzymatic determination of total serum cholesterol. Clin. Chem. 20:470-475.

Belay, T. K., B. S. Dagnachew, Z. M. Kowalski, and T. Ådnøy. 2017. An attempt at predicting blood $\beta$-hydroxybutyrate from Fouriertransform mid-infrared spectra of milk using multivariate mixed models in Polish dairy cattle. J. Dairy Sci. 100:6312-6326. https:/ /doi.org/10.3168/jds.2016-12252.

Benedet, A., C. L. Manuelian, A. Zidi, M. Penasa, and M. De Marchi. 2019. Invited review: $\beta$-Hydroxybutyrate concentration in blood and milk and its associations with cow performance. Animal. https://doi.org/10.1017/S175173111900034X.
Bjerre-Harpøth, V., N. C. Friggens, V. M. Thorup, T. Larsen, B. M. Damgaard, K. L. Ingvartsen, and K. M. Moyes. 2012. Metabolic and production profiles of dairy cows in response to decreased nutrient density to increase physiological imbalance at different stages of lactation. J. Dairy Sci. 95:2362-2380. https://doi.org/10 $.3168 /$ jds.2011-4419.

Butler, W. R., J. J. Calaman, and S. W. Beam. 1996. Plasma and milk urea nitrogen in relation to pregnancy rate in lactating dairy cattle. J. Anim. Sci. 74:858-865. https://doi.org/10.2527/1996 $.744858 \mathrm{x}$.

Chandler, T. L., R. S. Pralle, J. R. R. Dórea, S. E. Poock, G. R. Oetzel, R. H. Fourdraine, and H. M. White. 2018. Predicting hyperketonemia by logistic and linear regression using test-day milk and performance variables in early-lactation Holstein and Jersey cows. J. Dairy Sci. 101:2476-2491. https://doi.org/10.3168/jds 2017-13209.

De Marchi, M., V. Toffanin, M. Cassandro, and M. Penasa. 2014. Invited review: Mid-infrared spectroscopy as phenotyping tool for milk traits. J. Dairy Sci. 97:1171-1186. https://doi.org/10.3168/ jds.2013-6799.

Drackley, J. K., T. R. Overton, and G. N. Douglas. 2001. Adaptations of glucose and long-chain fatty acid metabolism in liver of dairy cows during the periparturient period. J. Dairy Sci. 84(Suppl.):E100E112. https://doi.org/10.3168/jds.S0022-0302(01)70204-4.

Esposito, G., P. C. Irons, E. C. Webb, and A. Chapwanya. 2014. Interactions between negative energy balance, metabolic diseases, uterine health and immune response in transition dairy cows. Anim. Reprod. Sci. 144:60-71. https://doi.org/10.1016/j.anireprosci.2013 .11 .007 .

González, F. D., R. Muiño, V. Pereira, R. Campos, and J. L. Benedito. 2011. Relationship among blood indicators of lipomobilization and hepatic function during early lactation in high-yielding dairy cows. J. Vet. Sci. 12:251-255. https://doi.org/10.4142/jvs.2011.12.3.251.

Gordon, J. L., S. J. LeBlanc, and T. F. Duffield. 2013. Ketosis treatment in lactating dairy cattle. Vet. Clin. North Am. Food Anim. Pract. 29:433-445. https://doi.org/10.1016/j.cvfa.2013.03.001.

Grelet, C., C. Bastin, M. Gelé, J.-B. Davière, M. Johan, A. Werner, R. Reding, J. F. Pierna, F. Colinet, and P. Dardenne. 2016. Development of Fourier transform mid-infrared calibrations to predict acetone, $\beta$-hydroxybutyrate, and citrate contents in bovine milk through a European dairy network. J. Dairy Sci. 99:4816-4825. https://doi.org/10.3168/jds.2015-10477.

Grelet, C., J. A. Fernández-Pierna, P. Dardenne, V. Baeten, and F. Dehareng. 2015. Standardization of milk mid-infrared spectra from a European dairy network. J. Dairy Sci. 98:2150-2160. https://doi .org/10.3168/jds.2014-8764.

Grelet, C., A. Vanlierde, M. Hostens, L. Foldager, M. Salavati, K. L. Ingvartsen, M. Crowe, M. T. Sorensen, E. Froidmont, C. P. Ferris, C. Marchitelli, F. Becker, T. Larsen, F. Carter, and F. Dehareng. 2019. Potential of milk mid-IR spectra to predict metabolic status of cows through blood components and an innovative clustering approach. Animal 13:649-658. https://doi.org/10.1017/ S1751731118001751.

Heuer, C., H. J. Luinge, E. T. G. Lutz, Y. H. Schukken, J. H. van der Maas, H. Wilmink, and J. P. T. M. Noordhuizen. 2001. Determination of acetone in cow milk by Fourier transform infrared spectroscopy for the detection of subclinical ketosis. J. Dairy Sci 84:575-582. https://doi.org/10.3168/jds.S0022-0302(01)74510-9.

Ingvartsen, K. L. 2006. Feeding- and management-related diseases in the transition cow. Physiological adaptations around calving and strategies to reduce feeding-related diseases. Anim. Feed Sci. Technol. 126:175-213. https://doi.org/10.1016/j.anifeedsci.2005 .08 .003 .

Jonker, J. S., R. A. Kohn, and R. A. Erdman. 1998. Using milk urea nitrogen to predict nitrogen excretion and utilization efficiency in lactating dairy cows. J. Dairy Sci. 81:2681-2692. https://doi.org/ 10.3168/jds.S0022-0302(98)75825-4.

Kohn, R. A., M. M. Dinneen, and E. Russek-Cohen. 2005. Using blood urea nitrogen to predict nitrogen excretion and efficiency of nitrogen utilization in cattle, sheep, goats, horses, pigs, and rats. J. Anim. Sci. 83:879-889. https://doi.org/10.2527/2005.834879x. 
Kume, S., K. Numata, Y. Takeya, Y. Miyagawa, S. Ikeda, M. Kitagawa, K. Nonaka, T. Oshita, and T. Kozakai. 2008. Evaluation of urinary nitrogen excretion from plasma urea nitrogen in dry and lactating cows. (Report). Asian-Australas. J. Anim. Sci. 21:1159 1163. https://doi.org/10.5713/ajas.2008.70734.

LeBlanc, S. 2010. Monitoring metabolic health of dairy cattle in the transition period. J. Reprod. Dev. 56:S29-S35. https://doi.org/10 $.1262 /$ jrd.1056s29.

Luke, T. D. W., S. Rochfort, W. J. Wales, V. Bonfatti, L. Marett, and J. E. Pryce. 2019. Metabolic profiling of early lactation dairy cows using milk mid-infrared spectra. J. Dairy Sci. 102:1747-1760. https://doi.org/10.3168/jds.2018-15103.

Macrae, A. I., D. A. Whitaker, E. Burrough, A. Dowell, and J. M. Kelly. 2006. Use of metabolic profiles for the assessment of dietary adequacy in UK dairy herds. Vet. Rec. 159:655-661. https://doi org/10.1136/vr.159.20.655.

McArt, J. A. A., D. V. Nydam, and G. R. Oetzel. 2012. Epidemiology of subclinical ketosis in early lactation dairy cattle. J. Dairy Sci. 95:5056-5066. https://doi.org/10.3168/jds.2012-5443.

McArt, J. A. A., D. V. Nydam, G. R. Oetzel, T. R. Overton, and P. A. Ospina. 2013. Elevated non-esterified fatty acids and $\beta$-hydroxybutyrate and their association with transition dairy cow performance. Vet. J. 198:560-570. https://doi.org/10.1016/j.tvjl .2013.08.011.

Pralle, R. S., K. W. Weigel, and H. M. White. 2018. Predicting blood $\beta$-hydroxybutyrate using milk Fourier transform infrared spectrum, milk composition, and producer-reported variables with multiple linear regression, partial least squares regression, and artificial neural network. J. Dairy Sci. 101:4378-4387. https://doi .org/10.3168/jds.2017-14076.

Raboisson, D., M. Mounié, and E. Maigné. 2014. Diseases, reproductive performance, and changes in milk production associated with subclinical ketosis in dairy cows: A meta-analysis and review. J. Dairy Sci. 97:7547-7563. https://doi.org/10.3168/jds.2014-8237.

Renaud, D. L., D. F. Kelton, and T. F. Duffield. 2019. Short communication: Validation of a test-day milk test for $\beta$-hydroxybutyrate for identifying cows with hyperketonemia. J. Dairy Sci. 102:15891593. https://doi.org/10.3168/jds.2018-14778.

Santschi, D. E., R. Lacroix, J. Durocher, M. Duplessis, R. K. Moore, and D. M. Lefebvre. 2016. Prevalence of elevated milk $\beta$-hydroxybutyrate concentrations in Holstein cows measured by Fourier-transform infrared analysis in Dairy Herd Improvement milk samples and association with milk yield and components. J. Dairy Sci. 99:9263-9270. https://doi.org/10.3168/jds.2016-11128.

Suthar, V. S., J. Canelas-Raposo, A. Deniz, and W. Heuwieser. 2013. Prevalence of subclinical ketosis and relationships with postpartum diseases in European dairy cows. J. Dairy Sci. 96:2925-2938. https://doi.org/10.3168/jds.2012-6035.

Tatone, E. H., T. F. Duffield, S. J. LeBlanc, T. J. DeVries, and J. L. Gordon. 2017. Investigating the within-herd prevalence and risk factors for ketosis in dairy cattle in Ontario as diagnosed by the test-day concentration of $\beta$-hydroxybutyrate in milk. J. Dairy Sci. 100:1308-1318. https://doi.org/10.3168/jds.2016-11453.

van der Drift, S. G. A., R. Jorritsma, J. T. Schonewille, H. M. Knijn, and J. A. Stegeman. 2012a. Routine detection of hyperketonemia in dairy cows using Fourier transform infrared spectroscopy analysis of $\beta$-hydroxybutyrate and acetone in milk in combination with test-day information. J. Dairy Sci. 95:4886-4898. https://doi.org/ $10.3168 /$ jds.2011-4417.

van der Drift, S. G. A., K. J. E. van Hulzen, T. G. Teweldemedhn, R. Jorritsma, M. Nielen, and H. C. M. Heuven. 2012b. Genetic and nongenetic variation in plasma and milk $\beta$-hydroxybutyrate and milk acetone concentrations of early-lactation dairy cows. J. Dairy Sci. 95:6781-6787. https://doi.org/10.3168/jds.2012-5640.

van Knegsel, A. T. M., S. G. A. van der Drift, M. Horneman, A. P. W. de Roos, B. Kemp, and E. A. M. Graat. 2010. Short communication: Ketone body concentration in milk determined by Fourier transform infrared spectroscopy: Value for the detection of hyperketonemia in dairy cows. J. Dairy Sci. 93:3065-3069. https://doi .org/10.3168/jds.2009-2847.

Visentin, G., M. Penasa, G. Niero, M. Cassandro, and M. De Marchi. 2018. Phenotypic characterisation of major mineral composition predicted by mid-infrared spectroscopy in cow milk. Ital. J. Anim. Sci. 17:549-556. https://doi.org/10.1080/1828051X.2017.1398055.

Wang, Q., and H. Bovenhuis. 2019. Validation strategy can result in an overoptimistic view of the ability of milk infrared spectra to predict methane emission of dairy cattle. J. Dairy Sci. 102:6288-6295. https://doi.org/10.3168/jds.2018-15684.

Wittwer, F. G., P. Gallardo, J. Reyes, and H. Opitz. 1999. Bulk milk urea concentrations and their relationship with cow fertility in grazing dairy herds in Southern Chile. Prev. Vet. Med. 38:159-166. https://doi.org/10.1016/S0167-5877(98)00121-4.

Xiaobo, Z., Z. Jiewen, M. J. Povey, M. Holmes, and M. Hanpin. 2010. Variables selection methods in near-infrared spectroscopy. Anal. Chim. Acta 667:14-32. https://doi.org/10.1016/j.aca.2010.03.048.

Zou, X., J. Zhao, and Y. Li. 2007. Selection of the efficient wavelength regions in FT-NIR spectroscopy for determination of SSC of 'Fuji'apple based on BiPLS and FiPLS models. Vib. Spectrosc. 44:220-227. https://doi.org/10.1016/j.vibspec.2006.11.005.

\section{ORCIDS}

A. Benedet (๑ https://orcid.org/0000-0003-4210-4273

M. Franzoi ๑ https://orcid.org/0000-0001-8701-5632

M. Penasa @ (ttps://orcid.org/0000-0001-9984-8738

M. De Marchi ๑ https://orcid.org/0000-0001-7814-2525 